\title{
SUDDEN LOSS OF SMELL IN THE DIAGNOSIS OF COVID-19 PATIENTS ATTENDING OPD-AN OBSERVATIONAL STUDY
}

\section{ENT}

Dr. G.Yugandhar

M.S(E.N.T)-Associate Professor - Dept..of E.N.T - Gitam Institute of Medical Sciences and Research(GIMSR)-Rushikonda,Visakhapatnam-45

Dr. Sanjeev Uday M.S(E.N.T)-Assistant Professor-Dept..of E.N.T-Gitam Institute of Medical Sciences and Srikar*

Research(GIMSR)-Rushikonda,Visakhapatnam-45.*Corresponding Author

\section{ABSTRACT}

Covid-19 out break is a major pandemic affecting many people in the entire world including India. In this study we studied the patients attending OPD with clinical features suggestive of upper respiratory infection(URI)and loss of smell and sent them for covid testing. Total 105 patients were studied in the study of which 27 patients were tested positive for covid-19. The above study suggests loss of smell to be considered as a significant clinical feature in covid19 patients and we can advise them to initiate social distancing and home isolation well before the result of covid test comes This can prevent the spread of disease to other people

\section{KEYWORDS}

Covid-19; Loss Of Smell; Anosmia; OPD Patients

\section{INTRODUCTION}

In the month of December 2019,pneumonia cases were identified in Hubei province in China(1)

The disease caused by Novel Corona virus and later the disease was spread to entire world and declared as pandemic by $\mathrm{WHO}(2)$

The main clinical features of this disease are cough, fever and myalgia and in some cases there is difficulty in breathing

There are many non specific symptoms also present

Loss of smell (Anosmia) is one of the such non specific clinical feature in many of the patients

Corona virus is known to cause loss of smell along with other symptoms of upper respiratoty infection

This study aims in diagnosis of Covid-19 disease (3) in petients presented with loss of smell,which helps in early isolation of the patient and prevents spread of disease to other before the diagnosis of Covid-19 confirmed by diagnostic test results comes, which may took 2-3 days

\section{MATERIALS AND METHODS}

The study was performed in two primary care hospitals

1.st.anns JM hospital - malkapuram — vizag

2.s.j hospital---Gajuwaka—vizag

\section{INCLUSION CRITERIA}

All the patients between the age group of $20-65$ years who comes to OPD with clinical features suggestive of URI along with loss of smell were included in this study

\section{EXCLUSION CRITERIA}

Patients who underwent nasal surgeries and who are suffering from nasal allergies and known case of sinusitis were excluded from the study

\section{RESULTS}

Data was collected from 105 patients who attended OPD from the month of Apr 2020 to August 2020

Among the 105 patients 67 patients were males and 38 were females No. of patients with anosmia

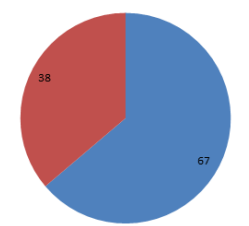

Fig1-Male, female ratio of patients with URI along with loss of smell

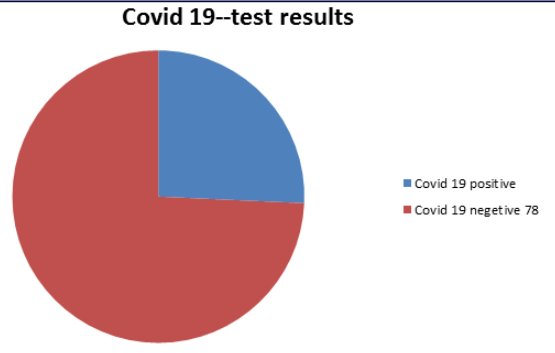

Fig2-Prevalance of anosmia in patients who were tested covid positive Out of 105 patients 27 were tested positive for covid 19

Thus the prevalence of anosmia in covid 19 patients was $28.35 \%$

Out of total 27 covid positive patients only 9 patients were admitted in various covid hospitals and took treatment and the rest of the 18 patients took medication with home isolation only

All the 9 patients were discharged after covid19 negetive result at the end of 14days

After 14 days 18 patients had regained the sense of smell

All the patients who were not in follow up were contacted on telephone at the end of 3 weeks and all the patiens had regained the sense of smell by then

\section{DISCUSSION}

Covid-19 out break is a major pandemic affecting lakhs of people all over the world including India

Fever along with respiratory signs and symptoms are established clinical feartures of this disease

Most of the clinical features are atypical

Viral upper respiratory infection (URI)is a known cause of olfactory dysfunction

A recent study by Sunnak etal (4)suggested that nasal epithelial cells shows a high angiotensin converting enzyme(ACE2) expression in SARS-COV-2 infection and thus this may allowing wide viral entry.

This anosmia can be a possible atypical feature in Covid 19 patients

In our present study 105 patients who attended OPD with upper respiratory infection(URI)with loss of smell were tested for Covid 19 among which 27 were tested positive $(28.35 \%)$

Thus the prevalence of anosmia in patients withURI can be considered 
as a non specific clinical feature in Covid 19

\section{CONCLUSION}

Presence of anosmia can be considered as a non specific clinical feature in Covid-19 and early identification and isolation of the patient will help in decreasing the spread of disease to other people before the Covid-19 diagnostic test result comes

\section{REFERENCES}

Huang C, Wang Y, Li X, et al. Clinical features of patients infected with 2019 novel coronavirus in Wuhan, China. Lancet. 2020;395:497-506. doi: 10.1016/S01406736(20)30183-5.

2. World Health Organization. Coronavirus disease (COVID-19) outbreak. https://www.who.int. Accessed 11 Mar 2020

3. Gane SB, Kelly C, Hopkins C. Isolated sudden onset anosmia in COVID-19 infection. A novel syndrome? Rhinology. 2020;58(3):299-301. doi: 10.4193/Rhin20.11

4. Sungnak W, Huang N, Bécavin C, Berg M (2020) HCA lung biological network. SARSCoV-2 entry genes are most highly expressed in nasal goblet and ciliated cells within human airways. 